\title{
People's Intuitions About Intuitive Insight and Intuitive Choice
}

\author{
Yoel Inbar \\ Harvard University
}

\author{
Jeremy Cone and Thomas Gilovich \\ Cornell University
}

\begin{abstract}
How do people balance intuition and reason when making decisions? We report 6 studies that indicate that people are cued by the features of the decision problem to follow intuition or reason when making their choice. That is, when features of the choice resemble features commonly associated with rational processing, people tend to decide on the basis of reason; when features of the choice match those associated with intuitive processing, people tend to decide on the basis of intuition. Choices that are seen as objectively evaluable (Study 1A), sequential (Studies 1B and 3), complex (Study 2), or precise (Study 4) elicit a preference for choosing rationally. This framework accurately predicts people's choices in variants of both the ratio-bias (Study 3) and ambiguity-aversion paradigms (Study 4). Discussion focuses on the relationship between the task cuing account, other decision-making models, and dual-process accounts of cognition.
\end{abstract}

Keywords: intuition, reason, rationality, choice

I don't have reasons. I have instincts. —Sir Montagu Norman ${ }^{1}$

What should you do when intuition tells you one thing and rational analysis another? How should you choose, in other words, when there is a conflict between your head and your gut? Since the dawn of the Enlightenment it has generally been agreed, in scholarly circles at least, that the head should be sovereign. Logic and reason have long been seen as the surest guides to the truth and to effective action, and as safeguards against the wayward influence of emotion and unaided intuition. But recently the Enlightenment call has not been sounded as often or as loudly, and it can be hard to hear among all of the advice to heed intuition. People are now bombarded with the message that they should trust their intuitions and "go with their gut." In popular culture, individuals are told "not to overthink," to "listen with your heart," and, of course, to let "the force" be with them. Popular translations of the scholarly literature on intuition and judgment and decision making reinforce this advice (Gigerenzer, 2007; Gladwell, 2005; Klein, 1998), as does much of the scholarly literature itself (Bargh, 1997; Dijksterhuis, Bos, Nordgren, \& van Baaren, 2006; Wilson \& Schooler, 1991).

The grounds for such advice are not hard to discern. The psychological literature contains numerous examples of notable accuracy and insight attributable to intuition (Ambady, Bernieri, \& Richeson, 2000; Bargh, 1997; Dijksterhuis et al., 2006; Dunning \& Stern, 1994; Ellis, 1984; Hay, Young, \& Ellis, 1986; Wilson \&

Yoel Inbar, John F. Kennedy School of Government, Harvard University; Jeremy Cone and Thomas Gilovich, Department of Psychology, Cornell University.

This research was supported by National Science Foundation Research Grants SES0241638 and SES0922323. We thank Erica Billig, Nick Joseph, and Lynette Lee for serving as experimenters and Dennis Regan for his comments on an earlier draft of this article.

Correspondence concerning this article should be addressed to Yoel Inbar, Harvard Kennedy School of Government, 79 JFK Street, Cambridge, MA 02143. E-mail: yoel_inbar@harvard.edu
Schooler, 1991) and roughly an equal number of erroneous judgments and disastrous decisions that can be blamed on faulty rational analysis (Baron, 1988; Hall, 1980). But support can be found for all sorts of claims, even the most highly questionable, and the issue is hardly settled. Indeed, the psychological literature also contains countless examples of spectacularly faulty intuitive assessments (Denes-Raj \& Epstein, 1994; Gilovich, 1991; Gilovich, Griffin, \& Kahneman, 2002; Tversky \& Kahneman, 1982), and the very existence of modern technological society is a compelling argument for the power of analytic thinking.

In reality, very little is known about precisely when one should follow one's gut instincts and when one should obey the dictates of a rational analysis. One bankable principle is that one's intuitions can be trusted only when they have been "tuned" in an informative environment (Hogarth, 2001). The associative connections that are the core of intuition are almost certain to be misleading if they were formed in an environment containing largely unrepresentative information. This is what gives rise, for example, to a number of unwarranted stereotypes (Correll, Park, Judd, \& Wittenbrink, 2002; Judd, Blair, \& Chapleau, 2004; Levine \& Campbell, 1972; Ross, Amabile, \& Steinmetz, 1977). Exposure to films and television shows in which members of a particular ethnic group engage in a level of criminality that is disproportionately high relative to real-life crime statistics is likely to lead to a strong gut feeling that members of that group are dangerous. Such gut feelings can be overcome through the effortful exercise of conscious will (Devine, 1989; Fiske, 1989; Kawakami, Dovidio, \& van Kamp, 2005), but note that it is the mind's rational faculties that compel one to reject the stereotype. More generally, it is one's rational faculties that discern whether the pertinent data are tainted and whether an intuitive conclusion based on these data should therefore be rejected.

\footnotetext{
${ }^{1}$ Sir Montagu Norman served as the Governor of the Bank of England from 1920 to 1944.
} 
Another principle that may have merit is that the parallel processing of the intuitive system can give it an edge when the judgment or decision calls for the integration of a great many input cues under time pressure (Dijksterhuis, 2004). In other words, to the extent that the judgment or decision resembles the task of, say, face recognition, which requires the simultaneous, rapid processing of a very large number of cues, one may be well served by honoring one's intuitions. One may be well served by doing so, that is, when there isn't (or one isn't aware of) an appropriate algorithm for solving the judgment or decision problem analytically, or when the algorithmic solution takes too much time.

Hammond (1996) has observed that just as thinking can be ordered on a cognitive continuum from rational to intuitive, tasks can likewise be ordered on a continuum from those amenable to rational thought to those amenable to intuition. On Hammond's task continuum, features of "intuitive" tasks include multiple intercorrelated cues, less than perfect cue reliability, the lack of an organizing principle or algorithm to integrate cues, and limited time (p. 163). For example, a task in which many intercorrelated cues are simultaneously presented visually is considered more intuitive, whereas one in which a few noncorrelated cues are presented numerically is considered more rational. Hammond, Hamm, Grassia, and Pearson (1987) have shown that when the nature of a person's thinking along the cognitive continuum matches the task's position on the task continuum, task performance is at its highest. In other words, thinking intuitively enhances performance on tasks that are "intuition-like," and thinking rationally enhances performance on tasks that are "rationalitylike."

Hammond's analysis provides a useful starting point for examining how people resolve conflicts between their intuitive impulses and their rational calculations when making choices. Intuition and reason are generally regarded as two complementary modes of thought that operate in parallel (e.g., Epstein, 1994; Evans, 2007; Kahneman \& Frederick, 2002; Sloman, 1996; Stanovich, 2004). Thus, for any given problem decision makers might choose to rely on intuition, rational analysis, or a combination of both (Hammond et al., 1987). But intuitive and rational processes sometimes produce diametrically opposed responses to the same problem (Sloman, 1996). How do people typically resolve such conflicts? How do they determine whether an intuitive or rational approach is best suited to a specific decision, and how do they reconcile conflicting results produced by intuitive and rational thought? We conducted the present research to find out.

More specifically, we wanted to test the competing predictions of three rival hypotheses. The first is that people generally honor rational analysis. After all, despite the abundant urgings to follow one's intuition, rationality is still thought of as the jewel in the crown of cognition and people may feel a strong normative pull to decide rationally. The second hypothesis is that people generally follow their gut instincts. More specifically, we thought that the nature of people's anticipated counterfactual thoughts, if the decision were to turn out badly, might make them reluctant to go against their intuitions. That is, because an intuitive preference is automatic and unbidden, it is often experienced as something that is "given," and to choose otherwise can be seen as an act of hubris that is likely to be punished by an unwanted result (Risen \& Gilovich, 2007, 2008). People might anticipate, in other words, that if the outcome were to turn out badly after neglecting their intuition, they would kick themselves because they "knew" the right course to take but thought about it too much and led themselves astray. This is the sort of anticipatory counterfactualizing that makes people reluctant to change answers on multiple-choice tests (Kruger, Wirtz, \& Miller, 2005; Miller \& Taylor, 1995). To avoid the experience of mentally kicking themselves, people may avoid going against their intuitions.

The third hypothesis is that people may be cued by a resemblance between features of the task and features of intuitive or rational processing, a phenomenon we call task cuing. That is, people may be inclined to think they should follow their intuitions whenever the characteristics of the judgment or decision resemble the characteristics of intuitive processing, and they should follow the dictates of a rational analysis whenever the characteristics of the judgment or decision resemble the characteristics of rational processing.

Thus far, we have not formally defined the terms intuitive and rational. Most people are comfortable and conversant with the distinction and can readily call to mind examples of both kinds of thinking. But our task cuing account requires a more detailed specification of the features of rational and intuitive processing that might be matched to features of a given task. The idea that people employ two qualitatively different modes of thought has a long history in social psychology. James (1890/1950) distinguished between associative thought, which he held to be based on associations established by past experience, and reasoning, which he maintained is alone capable of analyzing new information. More recently, a great number of dual-process theories of reasoning have been proposed (Chaiken \& Trope, 1999), all premised on the idea that thinking proceeds in one of two modes: one that is relatively slow, controlled, and effortful, and another that is relatively quick, automatic, and easy. Among the most influential of these are the theories of Epstein (1994), Sloman (1996), and Kahneman (2003), all of whom used different terminology to distinguish what we refer to as intuitive and rational processing. Epstein called the first kind of thinking experiential and the second rational; Sloman distinguished between an associative and a rulebased system; and Kahneman, following Stanovich and West (2000), used the more generic terms System 1 and System 2. Although these accounts differ on some of the details of intuitive/ rational processing, there is widespread agreement on the core features of each: Intuition is thought to be effortless, associative, holistic, and inexact, whereas rational thought is seen as effortful, rule-based, sequential, and precise. Outside of academic psychology, furthermore, most people have a clear sense of what intuitive and rational thought "feel like" and readily agree with these characterizations.

We therefore hypothesized that a match between a feature of a given task and one of these core characteristics of intuition would lead people to honor their intuitive inclinations; conversely, a match between task features and any of the characteristics of rational thought should prompt people to follow a rational analysis. For example, because people tend to think of rational analysis as precise and objective, they are likely to think they should follow their heads when the choice problem they confront is one in which the rightness or wrongness of the decision can be precisely and objectively defined. In contrast, because they think of intuitive processes as relatively inexact and subjective, they are likely to think they should follow their gut instincts when the choice they 
confront is one that cannot be so precisely or objectively evaluated. The main feature of the choice problem (how precisely it can be evaluated) is matched to a prominent feature of rational versus intuitive processing (the precision of its output) and thereby cues a rational or intuitive response, respectively.

We conducted six studies designed to explore the task cuing hypothesis and to examine whether it provides a better description of people's decision processes than the two rival hypotheses outlined above. All of the studies ask participants, in different ways and in different contexts, whether it is best to decide on the basis of intuition or a deliberate, rational analysis. Additionally, the first four studies asked participants about a wide variety of different choices, allowing us to determine whether, above and beyond task cuing, our participants exhibited an overall preference to choose on the basis of intuition or reason.

\section{Study 1A: The Precision and Objectivity of Evaluation}

Rational thought often involves the application of normative rules and the consideration of explicit criteria. The rules and criteria often considered in rational thought can lead to assessments that one outcome is, say, twice as good as another on one dimension and two-thirds better on a second dimension. One economic policy might rationally be deemed better than another because it generates twice as many new jobs, or one military campaign might be rationally chosen over another because it is predicted that it will yield two-thirds fewer casualties. Intuitive thought, in contrast, often yields idiosyncratic, subjective, and imprecise preferences. One option can seem clearly better than another, but it's hard to know by how much and it's hard to express and justify the preference in terms that would be readily understood by others. One might have an intuitive sense that one dessert would cap a meal better than another, but it can be hard to justify the intuition in precise, verbalizable terms. According to the task cuing account, this implies that choices with objectively evaluable outcomes should cue a preference for rationality, whereas subjectively evaluable choices - that is, choices for which the standard of evaluation is personal, idiosyncratic, and imprecise - should cue a preference for intuition. This study tested that prediction.

\section{Method}

We created a list of 25 choice dilemmas, ranging from the trivial ("Selecting an entrée") to the consequential ("Choosing a college to attend"). Twenty-two Cornell University undergraduates first read a brief introduction stating that some decisions are "made mainly on the basis of 'intuition,' or by consulting the 'gut'" while others are made "mainly on the basis of 'reason,' or through rational analysis." They then rated each choice dilemma in terms of "the extent to which [it] should be based on intuition versus reason," using a 9-point scale anchored by should be based exclusively on "intuition" and should be based exclusively on "reason."2

A separate group of 28 respondents, who were recruited and completed the survey via an Internet website, read a different set of instructions stating that "for some decisions, one can objectively quantify whether the decision worked out well or poorly, whereas for others whether or not it worked out well or poorly is a matter of personal taste." They were then asked to rate each of the 25 choices in terms of the extent to which evaluation of the outcome was "an objective or subjective determination." These ratings were made on a 9-point scale anchored by mainly a subjective matter and mainly an objective matter.

\section{Results and Discussion}

For each set of ratings, we first assessed interrater reliability by following the procedure outlined by MacLennan (1993). Reliability was high both for the ratings of how much the decisions should be based on intuition versus reason $(\alpha=.94)$ and the ratings of the objectivity with which the choice outcomes could be evaluated $(\alpha=.89)$. We then computed, for each choice, the median rating of how much the decision should be based on intuition versus reason (with higher numbers indicating a stronger preference for rational choice) and the median rating of the objectivity with which the outcome could be evaluated (with higher numbers indicating more objectively evaluable outcomes). We based our analyses on these median ratings, with choice dilemma as the unit of analysis. ${ }^{3}$

Not surprisingly, there was considerable variability across choice dilemmas in participants' preferences for deciding on the basis of intuition versus reason. The median ratings ranged from a low of 3 ("Selecting a dessert at the end of a meal at a restaurant," "Selecting an entrée") to a high of 9 (choosing "one of two cities in which to locate a toxic waste dump"). The mean of these median ratings across the 25 choice dilemmas was 6.27 , significantly higher than the scale midpoint of $5, t(24)=3.81, p<.001, d=$ 1.55. Thus, there was something of an overall preference for choosing rationally.

More noteworthy, however, was the extent to which the variability in participants' responses across the different choice dilemmas was captured by the extent to which the different choices were thought to be objectively evaluable. Consistent with the task cuing hypothesis, the more participants thought that a decision was objectively evaluable, the more inclined they were to believe that it should be based on rational analysis, $r(25)=.89, p<.001$ (see Figure 1).

The results strongly support the task cuing hypothesis: The more a choice was seen as objectively evaluable, the more a rational approach was seen as the appropriate choice strategy. Thus, the match between a feature of the choice (objective evaluability) and a feature of rational thought (the application of precise evaluative criteria) cued rationality. Similarly, a match between imprecise, subjective outcomes and the idiosyncratic, subjective nature of intuitive thought cued intuition.

\section{Study 1B: Sequential Versus Holistic Choices}

As noted above, nearly all two-systems accounts characterize rational processing as sequential and intuitive processing as par-

\footnotetext{
${ }^{2}$ We conducted a replication with a group of 28 respondents who were asked how much they personally would choose on the basis of rationality versus intuition for each of the 25 choices. Reliability for these ratings was high $(\alpha=.93)$, and conducting the analyses reported in Studies $1 \mathrm{~A}-1 \mathrm{C}$ using these ratings (rather than ratings of how one should choose) produced nearly identical results.

${ }^{3}$ Results in Studies $1 \mathrm{~A}-1 \mathrm{C}$ were nearly identical when the analyses were performed on the mean ratings rather than the median ratings.
} 


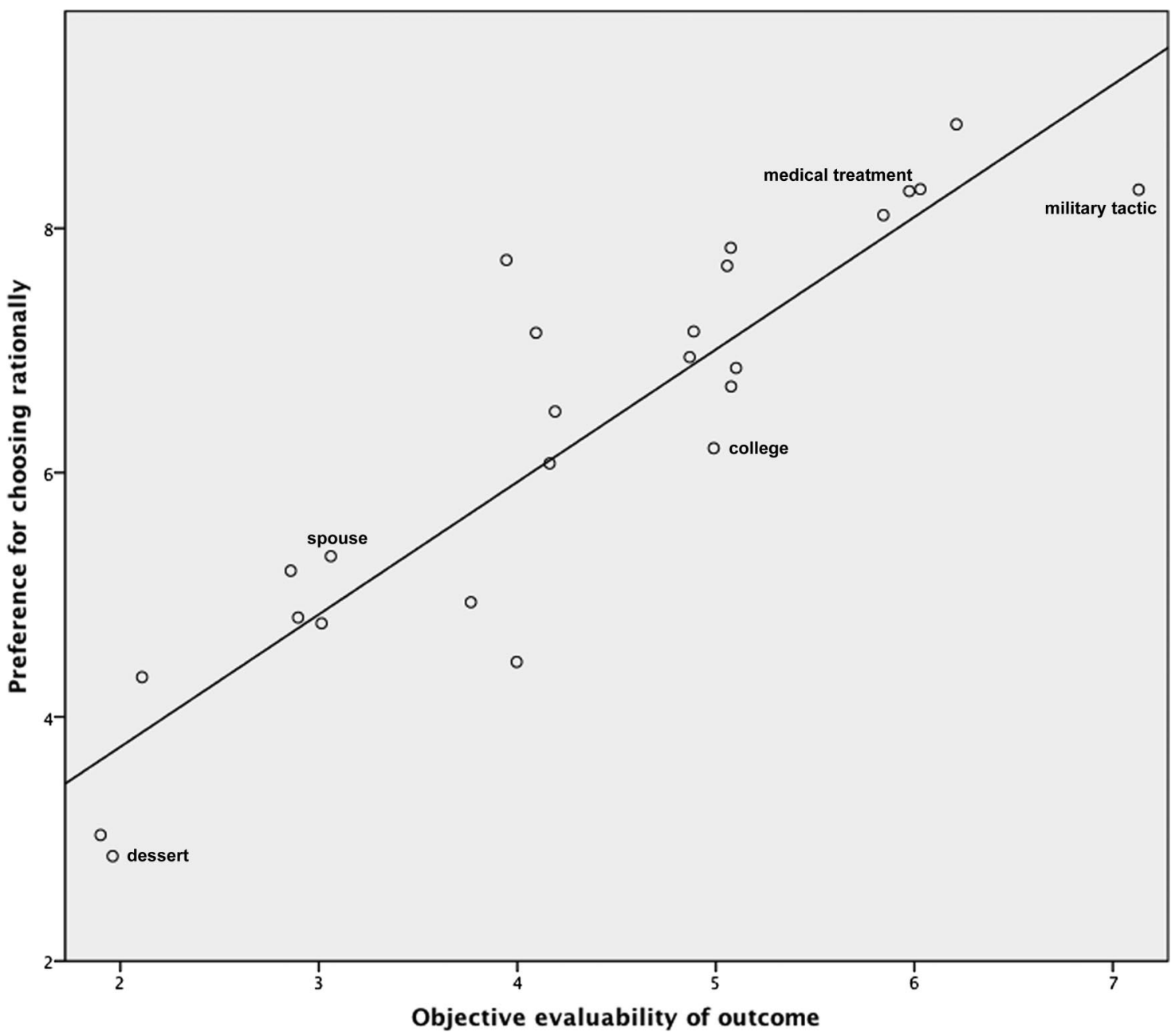

Figure 1. Relationship between evaluative precision and the tendency to decide rationally, Study 1A.

allel and holistic (Dijksterhuis, 2004; Epstein, 1991; Evans, 2007; Kahneman \& Frederick, 2002; Sloman, 1996; Stanovich, 2004). This fits the view among the general public that rational thinking proceeds step by step, whereas intuition comes in a flash. According to the task cuing hypothesis, then, decisions that are thought to consist of (or are embedded in) a series of discrete steps should cue rational processing, whereas those thought to be arrived at all at once should cue intuitive processing.

\section{Method}

Twenty-eight Cornell University undergraduates were asked to rate the same 25 choices used in Study 1A on the extent to which they tend to be made "all at once, taking into consideration all of the details at one time" versus through a "step-by-step, sequential process." Participants made their ratings on a 9-point scale, anchored at mainly holistic (1) and mainly sequential or step-by-step (9).

\section{Results and Discussion}

As in Study 1A, interrater reliability was high $(\alpha=.89)$. For each choice we computed the median rating of how much it was seen as being made sequentially (vs. all at once). We then correlated these ratings with the median ratings provided by the earlier group of 22 Cornell University students (from Study 1A) of how much each choice should be made intuitively or rationally. Consistent with the task cuing hypothesis, the more participants thought the decision encouraged sequential rather than holistic processing, the more they thought it should be based on rational analysis, $r(25)=.82, p<.001$ (see Figure 2).

In line with the results of Study 1A, the results of this study support the task cuing hypothesis. That is, the match between a prominent feature of some choices (serial processing) and a prominent feature of rational thought (step-by-step analysis) appeared to cue rationality, leading participants to endorse the wisdom of deciding on the basis of reason. Conversely, a match between the holistic evaluations encouraged by certain choices and the parallel processing of intuitive thought appeared to cue intuition, leading participants to endorse the wisdom of going with the gut.

\section{Study 1C: Multivariate Analysis}

The results of Studies 1A and 1B indicate that people believe that choices that permit objective evaluation (Study 1A) and that 


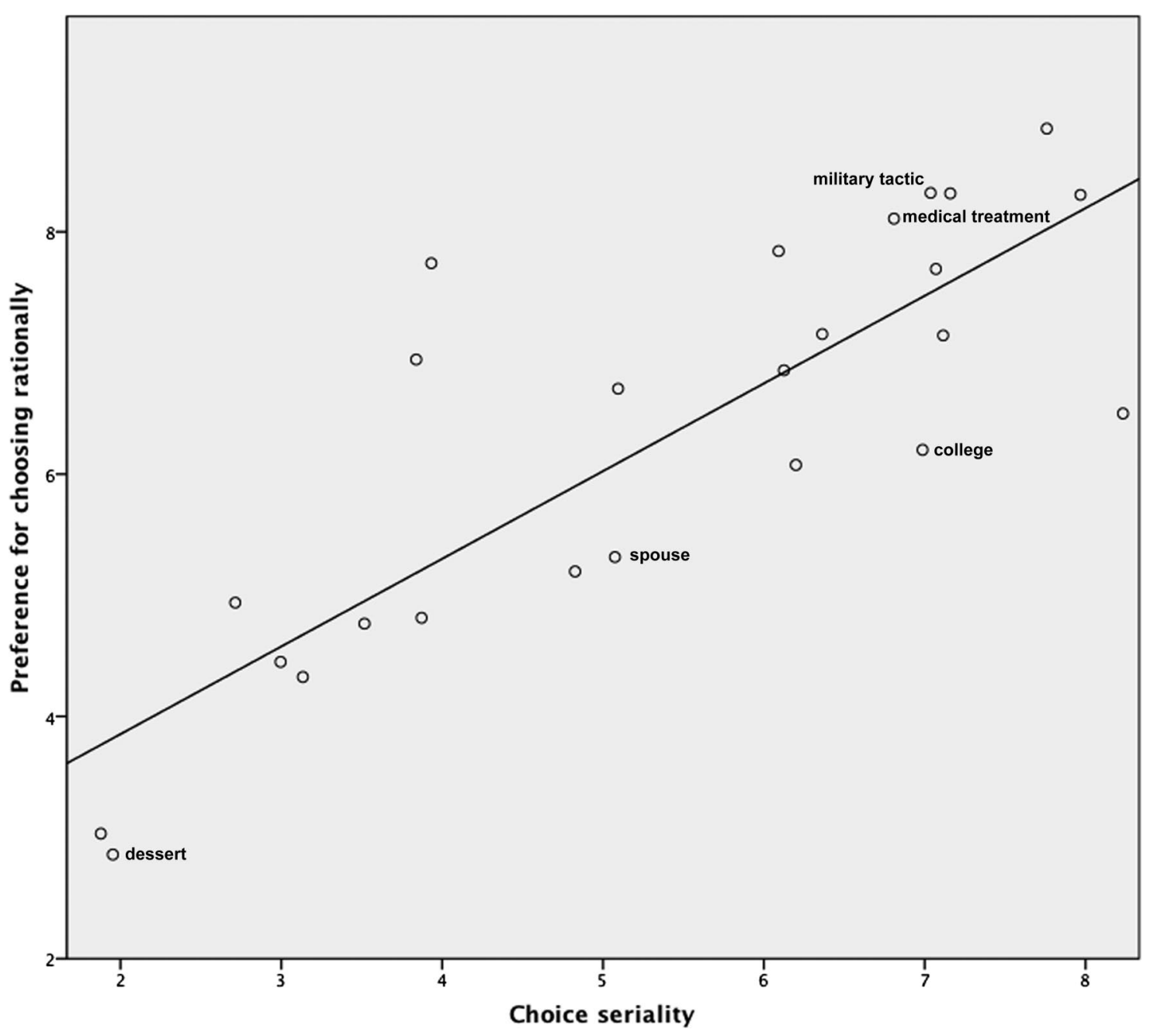

Figure 2. Relationship between choice seriality and the tendency to decide rationally, Study 1B.

consist of a series of discrete steps (Study 1B) should be decided on the basis of rational analysis. These data are correlational, however, and so it is possible that both objective outcome evaluability and stepwise processing correlate with some underlying variable that is responsible for the relationship between these choice features and a preference for choosing rationally. One plausible underlying variable is choice importance: It might be that more important choices are seen as having more objectively evaluable outcomes, involving more steps, and demanding a more rational analysis. The results of Studies $1 \mathrm{~A}$ and $1 \mathrm{~B}$ might therefore be an artifact of the effect of choice importance on the tendency to choose on the basis of rationality versus intuition.

It is also possible that the significant relationships we documented in Studies 1A and 1B are not independent. Perhaps outcome evaluability and the sequential nature of decision making are correlated, and only one of them is driving the connection to the preference for choosing intuitively or rationally.

To examine these possibilities, we asked an additional group of 27 respondents, who were recruited in via the same Internet website used in Study 1A, to rank our 25 choices from most to least important. The reliability of these rankings was high $(\alpha=$
96). We computed a median importance rank for each choice and reversed the scores so that higher numbers corresponded to more important choices. The interrelationships (computed across the 25 choice dilemmas) between these rankings, ratings of outcome evaluability and choice seriality, and preferences for choosing rationally are shown in Table 1 . To sort out the independent effects

Table 1

Intercorrelations Between Preferences for Choosing Rationally and Ratings of Choice Outcome Evaluability, Seriality, and Importance, Studies $1 A-1 C$

\begin{tabular}{lcccc}
\hline \multicolumn{1}{c}{ Variable } & 1 & 2 & 3 & 4 \\
\hline $\begin{array}{l}\text { 1. Preference for choosing } \\
\text { rationally }\end{array}$ & - & $.89^{* *}$ & $.82^{* *}$ & .28 \\
$\begin{array}{l}\text { 2. Objective evaluability } \\
\text { of outcome }\end{array}$ & & - & $.76^{* *}$ & .29 \\
$\begin{array}{l}\text { 3. Choice seriality } \\
\text { 4. Choice importance }\end{array}$ & & - & $.58^{*}$ \\
\hline$* p<.01 .{ }^{* * *} p<.001$. & & & \\
\hline$*$
\end{tabular}


of these variables on the tendency to choose rationally versus intuitively, we conducted a multivariate analysis in which we simultaneously regressed participants' preferences for choosing rationally versus intuitively (using the same ratings employed in Studies 1A and 1B) on the extent to which choice outcomes were seen as objectively evaluable (using ratings from Study 1A), choice seriality (using ratings from Study 1B), and choice importance (using the ratings collected from this new sample of participants).

The objectivity of outcome evaluation was associated with a preference for choosing rationally, $\beta=.58, t(21)=4.57, p<$ .001 , as was the sequential nature of the choice, $\beta=.48, t(21)=$ $3.21, p=.004$. The relationship between choice importance and the preference for choosing rationally was positive, but not significantly so, $\beta=.17, t(21)=1.68, p=.11$.

Supporting the task cuing hypothesis, the extent to which choice outcomes were seen as objectively (vs. subjectively) evaluable and the extent to which choices were seen as being step-by-step (vs. holistic) independently predicted the degree to which people thought those choices should be made rationally (vs. intuitively). This was true even when controlling for the perceived importance of the choice. These results thus rule out any concern that one of these relationships might be responsible for the other, or that either of them is an artifact of choice importance.

\section{Study 2: Option Complexity}

Rational thought is experienced as relatively effortful, whereas intuitive thought is experienced as relatively effortless or automatic. Thus, attributes of a choice that suggest effort or difficulty should cue rationality, whereas features that suggest ease should cue intuition. Consistent with this idea, participants who confronted problems presented in a difficult-to-read font evaluated those problems less impulsively and more rationally (Alter, Oppenheimer, Epley, \& Eyre, 2007; Simmons \& Nelson, 2006). Another attribute beyond disfluency that suggests effort is complexity: More complex choices tend to be seen as more demanding of effort, and hence, we would predict, as requiring more rational analysis. Simpler choices, in contrast, should be seen as more amenable to being determined by intuition.

To ensure that the task cuing hypothesis applies beyond the 25 choices used in Studies 1A-1C, we tested the role of complexity using a list of 40 consumer products developed by Dijksterhuis et al. (2006). These products varied in both price and complexity. Dijksterhuis et al. calculated a complexity score for each product by asking respondents how many aspects of the product they would take into account when making a purchasing decision. Objects ranged from quite complex (e.g., "computer," "car") to moderately complex (e.g., "curtains," "dress") to relatively simple (e.g., "brush," "toothpaste").

\section{Method}

We showed 31 volunteer participants, who were Cornell University students recruited on campus, the same brief description of rational and intuitive decision strategies used in Study 1 and then asked them to rate each product for how much they thought "the choice of what to buy should be based on intuition versus reason" using the same 9-point scale as before. Reliability of these ratings was high $(\alpha=.92)$, so we computed the median preference for choosing rationally for each product.

\section{Results}

As before, there was considerable variability across choice items in the extent to which participants thought it best to choose on the basis of intuition versus reason. The median preference for rationality scores varied from a low of 3 ("book") to a high of 8 ("car," "cell phone," "computer," and "plane ticket"). Overall, there was a preference for choosing on the basis of reason over intuition, reflected in an overall mean across the 40 products of 5.98, significantly above the scale midpoint of $5, t(39)=4.78, p<$ $.0001, d=1.53$.

Also as before, there was considerable support for the task cuing hypothesis. Product complexity (as reported by Dijksterhuis et al., 2006) correlated significantly with a preference for choosing on the basis of a rational analysis over intuition, $r(40)=.41, p<.01$ (see Figure 3). To examine the artifactual explanation that more expensive (and presumably more important) products are seen both as more complex and more apt to be chosen on the basis of rational analysis, we asked 21 volunteer participants to indicate what they thought the typical price of each product was. We then computed the median perceived price for each item. Although perceived complexity was positively correlated with perceived price, $r(40)=.28, p=.08$, the relationship between product complexity and the preference for choosing rationally remained significant when controlling for price, $r(37)=.34, p<.05$.

\section{Discussion}

Again, the results provide strong support for the task cuing hypothesis. More complex products elicited a preference for choosing rationally, whereas simpler products elicited preference for choosing intuitively. This relationship held when controlling for the perceived price of the choice objects, a possible confound. Once again, features of the task (complexity, and hence the difficulty of making a decision) were matched to features of rational versus intuitive thought (effortful processing), cuing an increased preference for rationality when complexity was high. Interestingly, this intuition on the part of our participants runs exactly counter to the position advocated by Dijksterhuis et al. (2006), who argued that when choices are complex, intuition produces better choices than does rational analysis.

\section{Study 3: Going With the Head or the Gut in the Ratio-Bias Paradigm}

The previous studies provide broad support for the task cuing hypothesis. When a given choice possesses features associated with rational thought, such as evaluative precision (Study 1A), sequential assessment (Study 1B), and complexity (Study 2), rational thought is cued and people tend to go with the head over the gut. When a choice possesses features associated with intuition, such as evaluative ambiguity, holistic assessment, and simplicity, intuitive processing is cued and people are more willing to go with intuition. Although the evidence obtained in the studies described thus far is broad-based, all of it concerns how people think one should choose-no actual choices were made. The next two stud- 


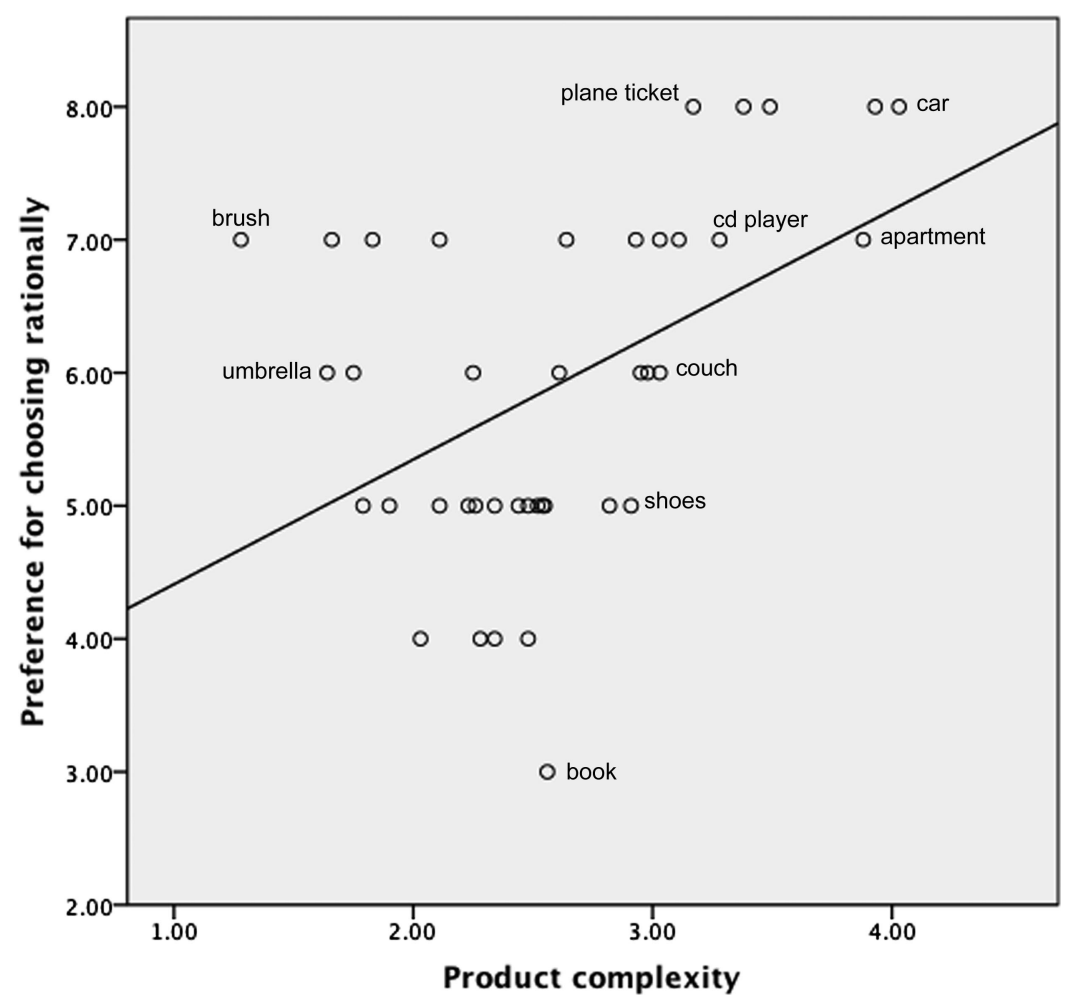

Figure 3. Relationship between product complexity and the tendency to decide rationally, Study 2.

ies examine whether the task cuing account predicts people's actual choices when confronted with a real conflict between intuition and reason. Furthermore, the evidence obtained in Studies 1 and 2 is correlational and hence is open to all of interpretative ambiguity associated with nonexperimental evidence. The next two studies examine the task cuing account experimentally.

To confront participants with a situation in which they are pulled in one direction by reason and another by intuition, we used the ratio-bias paradigm pioneered by Epstein and colleagues (Denes-Raj \& Epstein, 1994; Epstein, 1991). In this paradigm, participants are told that a token (typically a marble) is to be drawn at random from one of two jars and if a token of the winning color is selected, they will win a prize. One jar, the small jar, is known to contain one winning token and nine losers. The other jar, the large jar, is known to contain, say, nine winners and 91 losers. The key element is that the large jar is known to contain a greater number but a lower percentage of winners (here, $9 \%$ vs. $10 \%$ in the small jar). This creates in many participants a conflict between a gut attraction to the jar with a larger number of winners and the rational realization that the jar with the higher percentage offers the best chance of winning.

In our study, the drawing was to win a freshly baked cookie and participants were randomly assigned to one of two conditions. In the holistic condition, the outcome of the draw would directly determine whether or not participants would win the cookie. In the sequential condition, the draw was the first step in a sequence of tasks that could lead to receiving the cookie. That is, a successful draw would earn participants points and the total number of points they earned across three separate tasks would determine whether they would win the cookie. The placement of the drawing as one step in a sequence of events was emphasized in a schematic diagram meant to cue rational processing. We were interested in whether participants in the sequential condition would accordingly find their rational impulses more compelling and hence be more inclined than their counterparts in the holistic condition to choose to draw from the smaller jar (with only one winner, but a higher percentage likelihood of winning).

This procedure, of course, confounds the sequential versus all-at-once nature of the outcome with whether the drawing constitutes merely one determinant of the outcome or the full determinant. But note that there is no reason, beyond our analysis, to believe that people tend to reason rationally about component outcomes but intuitively about final outcomes. Note also that if participants deemed the choice less important in the sequential condition (because it represents only one step in the possible receipt of the cookie), they should be more likely to make the intuitive choice because of the association between task importance and a preference for rational choice we observed in Study 1C. This would therefore work against our hypothesis.

\section{Method}

Participants. Forty-one Cornell University undergraduates enrolled in psychology or human development classes participated in exchange for academic credit.

Materials. Two transparent glass jars containing blue and yellow foam pieces were clearly visible on the desk at which participants were seated during the lab session. The jars were of 
equal size but contained different numbers of foam pieces: One contained 1 blue and 9 yellow pieces; the other contained 9 blue and 91 yellow pieces. An index card placed in front of each jar was labeled with both the absolute composition of the jar and the percentage of blue pieces it contained (e.g., "This jar contains: 1 blue foam shape and 9 yellow foam shapes [10\% blue]").

In the sequential condition, a number of additional supplementary materials were placed on the desk to bolster the notion that participants would be completing more than one task: a sheet of paper containing blank lines labeled "Word \#1:", "Word \#2:", and so forth, purportedly to be used in a word generation task, as well as a collection of seven cardboard shapes purportedly to be used in a spatial task (described below).

Procedure. Subjects were informed that, in addition to receiving course credit for participating, they would have an opportunity to win a freshly baked cookie by having the experimenter draw, without looking, from one of two jars containing blue and yellow pieces. The role of the outcome in obtaining the cookie differed by condition. In the holistic condition, subjects were told that if the experimenter drew a blue piece from the selected jar, they would receive the freshly baked cookie; their only task was to choose which of the two jars to draw from.

In the sequential condition, participants were told that the drawing was the first in a sequence of three tasks that would determine whether they would win the cookie. Each of the three tasks gave them the opportunity to earn points, and their overall point total at the conclusion of the third task determined whether they would win the cookie. The experimenter explained that if a blue piece was drawn from the selected jar, the participant would carry 20 points into the second task. If a yellow piece was drawn, the participant would begin the second task with 0 points, thus making the goal of achieving a sufficient number of points in the second task considerably more difficult.

The second task in the sequential condition was described as a word formation task in which subjects would be given a word (e.g., spontaneous) and asked to form as many words as possible using only the letters contained in the target word (e.g., tan). They were told that their goal was to accumulate 40 points and, if they did so, they could move on to the third task, a variant of the Chinese spatial puzzle game Tangrams. If they had less than 40 total points at the conclusion of the second task, they would receive only academic credit and no cookie. If they made it to the third task, they would receive the cookie if they earned 10 or more points making Tangrams. To highlight the sequential nature of the three tasks and their role in obtaining the cookie, we summarized the contingencies in a flow chart placed directly in front of the two jars (see Figure 4).

In both conditions, following the exposition of the drawing procedure, the experimenter, who was not informed of the hypothesis under investigation, reiterated the overall percentage of blue pieces in each of the jars and gave subjects a moment to think about their decision. ${ }^{4}$ Once participants verbally indicated their choices, the experimenter blindly drew once from the selected jar. If a blue piece was drawn, regardless of condition, participants were given a freshly baked cookie and then debriefed, thanked, and dismissed (i.e., participants in the sequential condition did not actually perform the last two tasks).

\section{Results and Discussion}

As predicted, when the decision was presented in a context that encouraged participants to think of it as sequential, it appeared to cue rationality: A majority (70\%) chose to draw from the smaller urn with only one winning piece but a higher percentage of winners. In contrast, when the decision was presented in a holistic, all-at-once context, it appeared to cue intuition: Only a minority $(38 \%)$ chose to draw from the smaller urn that offered the greater chance of winning. This difference was statistically significant, $\chi^{2}(1, N=41)=4.19, p<.05$.

Thus, task cuing does not simply influence people's thoughts about the proper decision strategy when considering hypothetical decision scenarios. It also influences how they resolve conflicts between intuition and reason in authentic decision contexts with real consequences. The ratio-bias paradigm confronts participants with a marked conflict between an intuitive impulse (to choose the lower probability urn with more winners) and their rationally derived better judgment (to choose the higher probability urn despite its having only one winner). How they resolve that conflict is influenced by features of the decision context in which it is embedded-features associated with either intuitive or rational thought. Our task cuing account thus receives support from an experimental paradigm in which the same conflict between intuition and reason is resolved differently depending on whether participants are encouraged to think of the choice problem as sequential or holistic.

But might subjects in the sequential condition have cared more about the outcome of the draw and chosen rationally more often because they were more motivated? Could they have wanted the cookie more, for example, because they had to go through more steps to get it (Aronson \& Mills, 1959; Cooper, 1980)? Or did they especially want to win the drawing so they could "coast" on the two subsequent, more substantive tasks? We have no way of knowing whether subjects in the sequential condition were motivated to win, but note that the opposite claim is equally plausible: that participants in the holistic condition were more motivated to win because the reward (the cookie) was just one step away from being achieved and hence was more psychologically impactful. More important, though, greater motivation on the part of subjects in the sequential condition cannot explain our results because past research using the ratio-bias paradigm has shown that greater motivation, if anything, increases the tendency to choose intuitively, not rationally. That is, subjects who are less inclined to process information rationally (as assessed by the RationalExperiential Inventory; Epstein, Pacini, Denes-Raj, \& Heier, 1996) tend to choose from the larger (intuitive) bowl more often when the stakes are raised; the choices of those who engage in more rational processing tend not to be affected by incentives (Pacini \& Epstein, 1999).

\footnotetext{
${ }^{4}$ We use the phrase "was not informed" instead of "was blind to" or "was unaware of" because when we afterwards asked the experimenter to state what she thought the hypothesis was, her guess was remarkably close to the actual hypothesis. These results should thus be interpreted with some caution and our thesis must rest more heavily on the results of the conceptual replication of this study offered by Study 4 (in which the experimenter did not articulate something close to the hypothesis) and, of course, on the results of Studies $1 \mathrm{~A}-1 \mathrm{C}$ and Study 2.
} 


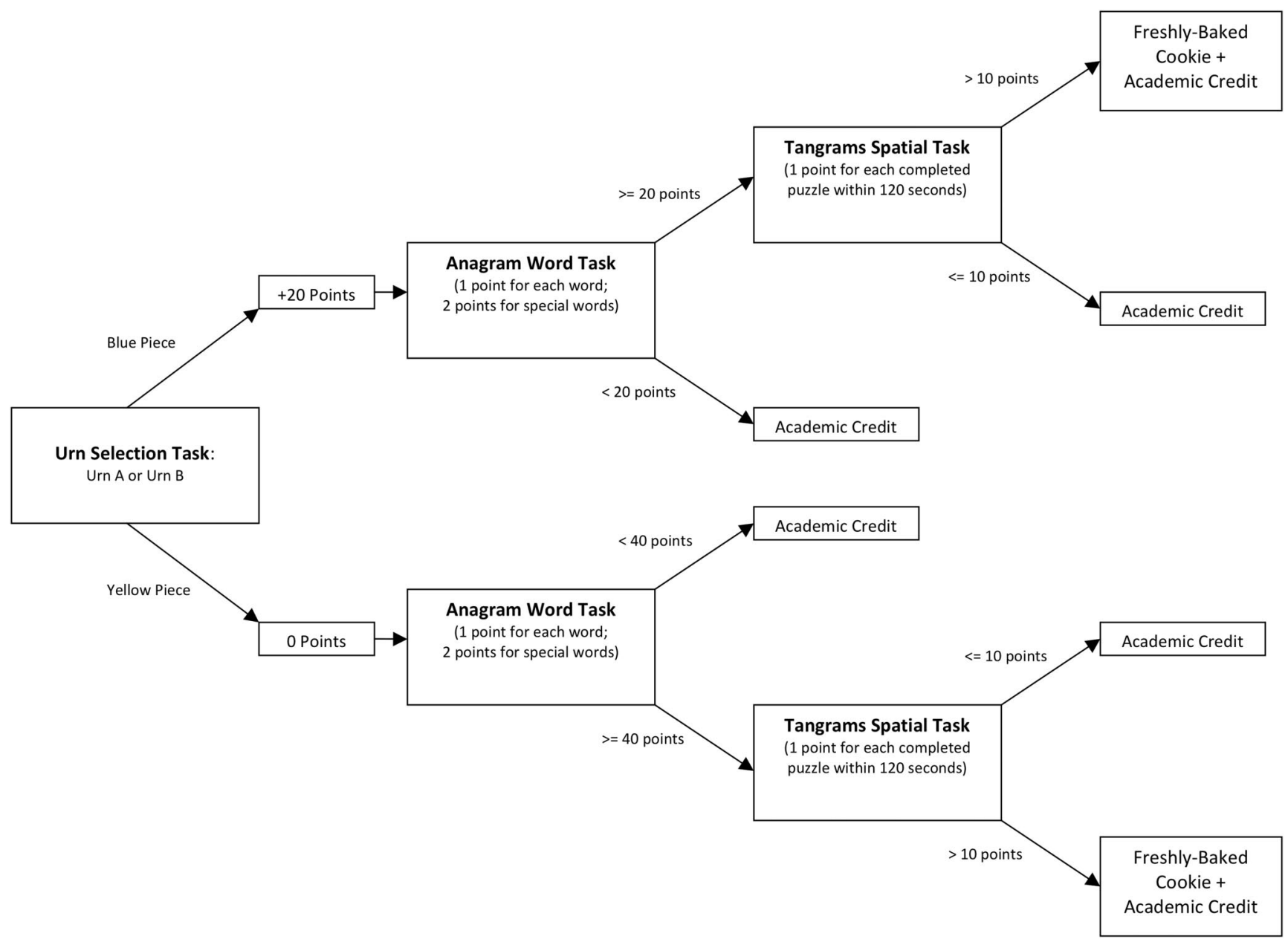

Figure 4. Schematic diagram shown to participants in the sequential condition depicting how the outcome of the ratio-bias task fits into the chain of events that could win them a freshly baked cookie.

\section{Study 4: Going With the Head or the Gut in the Ambiguity-Aversion Paradigm}

Rational thought is often precise. In choosing a college, we might rationally decide that it's wiser to pay $\$ 33,696$ in tuition than $\$ 37,750$. In choosing a car, we might rationally opt for one that gets 36 miles per gallon over one that gets 33. Indeed, rational thought often involves the use of formulas, which consist of strict rules and clearly specified inputs and outputs. Intuition, in contrast, is often imprecise. It often consists of affectively based preferences (Schwarz, 1990) and "good enough" heuristics (Gigerenzer, 2007; Gilovich et al., 2002).

According to the task cuing hypothesis, because people associate rationality with precision and intuition with imprecision, describing a task in precise terms should cue rationality and lead people to resolve a reason-intuition conflict in favor of reason. In contrast, describing a task in vague terms should cue intuition and lead people to resolve a reason-intuition conflict in favor of intuition. We tested this prediction here.

We sought to create a tension in participants between their rational and intuitive impulses by using a paradigm that evokes ambiguity aversion, or the preference for known risks over unknown risks. Thus, people are more willing to bet on drawing a winning marble from a bowl with $50 \%$ winners than a bowl with any possible percentage of winners (and hence an expected even chance of winning; Keynes, 1921). In our study, we asked participants to choose one of two bowls for a random drawing with a $\$ 10$ prize. Each bowl contained both red (winning) and clear (losing) marbles. One bowl, the known bowl, was uncovered and contained 50 red marbles and 50 clear marbles. The second bowl, the unknown bowl, was covered and so its precise contents were unknown to participants. However, they were given information indicating that, on average, the odds of drawing a red marble from the unknown bowl exceeded $50 \%$. Thus, a rational analysis focusing on the expected value of the two bowls should produce a preference for the unknown bowl. Ambiguity aversion, however, should produce an intuitive reluctance to draw from that bowl. Thus, we expected participants to experience a tension between their intuitive and rational preferences.

To test the task cuing hypothesis, we described the contents of the two bowls precisely or imprecisely. We predicted that a precise 
description would cue rational responding and therefore lead to a preference for the unknown (but statistically superior) bowl. We predicted that an imprecise description, in contrast, would cue intuitive responding and therefore lead to a preference for the known (and intuitively more appealing) bowl.

\section{Method}

Participants were 62 Harvard University undergraduates and Boston area residents who were randomly assigned to the precise or imprecise condition. Participants were seated in front of a table on which were two bowls, one covered and one uncovered. The experimenter, who was unaware of the hypothesis, explained that the study involved "two simple games of chance" and that if participants won both games they would win $\$ 10$ in addition to the $\$ 10$ show-up fee. (The second game was one in which participants predicted the outcome of a die roll; it was included to reduce the number of participants who won and would need to be paid the extra \$10.) The experimenter went on to explain that in the first game, the participant would choose one of two bowls from which the experimenter would select, without looking, a single marble. If a red marble was selected, the participant would win the game. Participants then completed a comprehension check to ensure they understood that a red marble meant winning the game and a clear marble meant losing. (If participants were confused at this point, the experimenter reviewed the rules.)

The experimenter then described the contents of the two bowls. In both conditions, she explained that each bowl contained 100 marbles and that the composition of the unknown bowl was randomly determined each day. However, the description of the two bowls differed between conditions: In the precise condition, the experimenter described the known bowl as containing "exactly 50 red marbles and 50 clear marbles" and the unknown bowl as containing "at least two" red marbles out of the 100, adding that "any number of red marbles from exactly two all the way up to 100 is equally likely." In the imprecise condition, the experimenter described the known bowl as containing "about 50 red marbles and 50 clear marbles" and the unknown bowl as containing "at least a few" red marbles, adding that "any number of red marbles, from just a few all the way up to 100 is equally likely." Thus, in both conditions the unknown bowl was described as offering superior odds compared to the known bowl. (With a uniform distribution of winners from 2 to 100 , there is a $50.5 \%$ chance of a winning draw from the unknown bowl. With the most likely interpretations of "a few" ranging from two to five, the chances of a winning draw from the unknown bowl in the imprecise condition are even higher.)

Note that this procedure stacks the deck against the task cuing hypothesis (which entails that participants will be more inclined to select from the covered, ambiguous bowl with superior odds in the precise condition). In the precise condition, the composition of one bowl is completely unambiguous and so ambiguity aversion should make that bowl particularly attractive. In the imprecise condition, even the 50:50 bowl is only approximate and so the contents of both bowls are ambiguous. This should make the unknown bowl relatively less troublesome from the standpoint of ambiguity aversion and therefore lead more participants to choose it. Nevertheless, we predicted that the effect of task cuing would be sufficiently strong that participants in the precise condition would find the rational argument for choosing the unknown bowl (i.e., better odds) so compelling that they would overcome the pull of ambiguity aversion and to choose the unknown bowl.

Once participants had verbally chosen a bowl, the experimenter drew a marble from it without looking. If a red marble was drawn, participants played the filler die roll game. All participants then completed a second questionnaire to ensure they correctly understood the description of the covered bowl. The questionnaire consisted of two true-false questions: "The 'hidden bowl' contained at least two winning (red) marbles," and "the 'hidden bowl' was equally likely to contain any number of winning (red) marbles from two to 100." Participants who won both games were then paid $\$ 20$; the rest were paid $\$ 10$.

\section{Results and Discussion}

Thirteen participants gave incorrect answers to one or both questions on the second comprehension check (no participant failed the first comprehension check) and so their data were excluded from the analysis. These participants were roughly evenly divided between the imprecise $(n=8)$ and precise conditions $(n=5)$.

As predicted, participants were significantly more likely to choose the unknown (but statistically superior) bowl if the choice was described in precise terms than if it was described in approximate terms. In the precise condition, $50 \%$ of participants chose the unknown bowl, compared to $22 \%$ in the imprecise condition, $\chi^{2}(1$, $N=49)=4.19, p<.05$. These results provide strong support for the task cuing account. Despite the fact that there was more of a difference in ambiguity between the two conditions in the precise condition, the very precision of the descriptions offered in that condition appeared to cue rationality. This made the rational impulse to go with the superior odds more compelling than the intuitive impulse to avoid ambiguity. In contrast, participants who heard an inexact description of the two bowls gave in to the intuitive pull of ambiguity aversion by a large margin.

To manipulate precision, we described the contents of the two bowls in different ways. Might these differences in wording have artifactually produced the observed difference in participants' choices? We do not believe so. Indeed, as stated earlier, the differences in wording should, if anything, have led to the opposite pattern of results. In the precise condition, the unknown bowl was described as containing at least two winners, whereas in the imprecise condition it was described as containing "a few." Given the most common interpretation of "a few" (i.e., three), the unknown bowl should have been more attractive in the approximate condition-precisely the opposite of what was observed.

\section{General Discussion}

Psychologists have recently placed great emphasis on the crucial role that intuition plays in people's everyday decisions (Gigerenzer, 2007; Kahneman \& Frederick, 2002; Klein, 1998) and beliefs (Haidt, 2001), and this emphasis on the power of intuition is reflected in popular treatments of psychology as well (Gladwell, 2005; Myers, 2002). Much of the research on intuition has focused on buttressing the claim that intuitive impulses often give rise to decisions that are superior to those arrived at via deliberate thought (Dijksterhuis et al., 2006; Wilson \& Schooler, 1991). Although it is certainly important to understand the circumstances under which 
intuition leads to better or worse decisions, it is also important to understand when and how people choose to decide rationally or intuitively. The current research was undertaken as one step toward such an understanding.

Across six studies, participants exhibited a pronounced sensitivity to features of the decision at hand when deciding whether to choose on the basis of intuition or reason. People overwhelmingly believe that reason should hold sway when choosing stocks or schools but that intuition should be sovereign when it comes to choosing desserts or dating partners. The task cuing account appears to go a long way toward explaining why. When the decision task has features associated with reason, it cues rationality, making rational arguments for a given choice more compelling, so that people obey the head. When the decision task has features associated with intuition, it cues intuitive processes, making intuitive arguments for a given choice more compelling, so that people obey the gut.

In support of this analysis, Studies $1 \mathrm{~A}, 1 \mathrm{~B}$, and 2 found that the degree to which participants said they would choose on the basis of reason was directly proportional to the degree to which different decisions possessed features typically associated with reasonevaluative precision (Study 1A), serial processing (Study 1B), and complexity (Study 2). Task cuing also influenced whether participants obeyed their rational or intuitive impulses when faced with real intuition-reason conflicts with real financial consequences and when the features of the choice problem that cued rational or intuitive responses were experimentally manipulated. In Study 3, participants faced with an intuition-reason conflict in a ratio-bias paradigm were more likely to make the rational choice when the choice problem contained cues to the serial processing characteristic of reason. In Study 4, participants faced with an intuitionreason conflict in an ambiguity-aversion paradigm were more likely to make the rational choice when the choice problem contained the precision cues also characteristic of reason.

A number of models of decision making address how people choose a cognitive strategy on the basis of features of the task or the decision environment. Of these, the most relevant to our task cuing account are Beach and Mitchell's (1978) contingency model of strategy selection, Payne, Bettman, and Johnson's (1993) adaptive decision maker framework, and Hammond and colleagues' cognitive continuum theory (Hammond, 1996; Hammond et al., 1987).

\section{Beach and Mitchell's Contingency Model}

According to Beach and Mitchell (1978), decision makers possess a repertoire of decision-making strategies, which can be divided into three classes: aided analytic, unaided analytic, and nonanalytic. Aided-analytic strategies involve effortful computation and the use of some kind of decision tool or aid. Formal decision analysis, the use of a decision algorithm, or simply listing the pros and cons of various options would all be considered aided-analytic strategies. Unaided-analytic strategies involve attempts to weigh the pros and cons of various options "in the head," without decision aids. Attempts to mentally simulate the outcomes of different choices, for example, would be considered an unaidedanalytic strategy. Finally, nonanalytic strategies consist of simple rules such as "flip a coin," "choose the same way I chose last time," and "choose what everyone else is choosing." It is assumed that aided-analytic strategies are the most effortful, nonanalytic strategies are the least effortful, and decision makers tend to match the effortfulness of the strategy to the perceived demands of the task.

Beach and Mitchell (1978) discussed a number of task features that decision makers tend to interpret as demands to process more effortfully, including one that we examined here: choice complexity. Thus, there is some overlap between the two accounts in the features of choices that are thought to produce a preference for choosing rationally. There are, however, important differences between the two accounts. The first concerns how "nonrational" thought is viewed. According to Beach and Mitchell's model, nonrational thought consists solely of simple rules of thumb, and decision makers view nonrational thought as appropriate only when task demands are low. ${ }^{5}$ In contrast, the task cuing account allows for the possibility that people view intuition as an appropriate and valuable input into complex decision making and that decision makers often prefer to decide on the basis of intuition even for important choices. This leads to a second important difference between the two models: The contingency model posits that variability along a single dimension determines the extent to which different tasks engage more or less rational processingperceived need for effort. In contrast, the task cuing account allows the matching of intuitive and rational thought to a wide variety of features of the choice task.

\section{The Adaptive Decision Maker Framework}

Payne et al.'s (1993) adaptive decision maker framework is similar to the contingency model in that it posits that decision makers choose, depending on the demands of the task, from a range of strategies that vary in effort and accuracy. However, the adaptive decision maker framework focuses on quantifying the amount of effort thought to be demanded by various strategies, and on measuring - using both computer simulations and process tracing procedures in actual decisions-the effort-accuracy trade-offs between different strategies. The best strategies are assumed to be generally more effortful. For example, the weighted additive strategy, in which each feature of each option is weighted by its importance and then added to the total score for that option, is assumed to be the most effective (because it weights and integrates all the available information). But it is also the most effortful because it involves carrying out many operations for each option. In contrast, the lexicographic strategy, in which the most important attribute is determined and the alternative which scores highest on that attribute is selected, is less effortful but also typically less effective.

Like Beach and Mitchell's (1978) contingency model, the adaptive decision maker framework postulates that strategy selection is determined by features of the decision task. However, the focus is on processing requirements that might exceed the decision maker's capacity, prompting a fall-back to a less demanding strategy. For example, a more complex set of choice options increases process-

\footnotetext{
${ }^{5}$ Beach and Mitchell have since proposed image theory (Beach, 1990; Mitchell \& Beach, 1990), which attempts to include a larger role for intuitive thought in decision making. However, because image theory deals exclusively with the perceived acceptability of a single option (as opposed to choices between two or more options) it is not discussed further here.
} 
ing demands, and time pressure limits one's ability to meet them, and so both prompt a reliance on simpler, less effortful strategies. ${ }^{6}$

The most important difference between the adaptive decision maker framework and the task cuing account is that the former deals exclusively with choice strategies that are at least somewhat deliberate (although varying in effort). According to the adaptive decision maker framework, even a low-effort strategy, such as a lexicographic decision rule, constitutes a form of rational analysis. The quick, holistic, and idiosyncratic assessments that are the core of intuition are largely ignored. Thus, the adaptive decision maker framework is best suited to addressing the circumstances under which decision makers prefer to use different types of deliberative decision strategies, rather than how they choose between intuition and reason.

\section{Cognitive Continuum Theory}

Hammond's (1996) cognitive continuum theory (CCT) is alone among the strategy selection models discussed here in explicitly acknowledging the role of intuition in decision making. According to CCT, just as thinking can be described as relatively rational or intuitive on a cognitive continuum, tasks can be described as rationality-inducing or intuition-inducing on a task continuum. Tasks are assumed, through an unspecified process, to induce a type of cognitive activity that matches their position on the task continuum. Furthermore, accuracy is thought to be maximized when the location of a decision maker's approach along the cognitive continuum matches the position of the task on the task continuum (Hammond et al., 1987). Task characteristics thought to induce intuition include the existence of a large number of relevant cues, high redundancy among cues, and perceptual (as opposed to objective) measurement of cue values.

Thus, there is not a great deal of overlap between CCT and the task cuing account in terms of the task characteristics that are thought to induce intuitive or rational processing. This is likely the result of the different kinds of decisions that are the focus of the two theories: As an outgrowth of judgment analysis (Cooksey, 1996), CCT is well suited to decisions for which the inputs are relatively well specified and accuracy can be defined objectively. CCT is less well suited to decisions in which the clear isolation of different cues, and the definition of what constitutes a successful outcome, is more difficult. For example, choice options involving multiple redundant cues, assessed perceptually, are typical of a great many of the "real-world" choices addressed by the task cuing account (consider the number of intercorrelated cues involved in choosing between cars or apartments, let alone dating partners). According to CCT, such decisions should strongly prompt intuitive processing, yet, as we have shown, people prefer to make many of these decisions rationally.

The second major difference between the two theories is that the task cuing account addresses a question that CCT does not: How does a decision task elicit a preference for deciding on the basis of intuition or reason? CCT does not offer an explanation for how tasks induce intuition or reason; it simply assumes that they do. In contrast, the task cuing account makes explicit that it is the match between task characteristics and characteristics of intuition or reason that leads to the cuing of intuitive or rational choice.

\section{Task Cuing and Dual-Process Models of Cognition}

Among the many dual-process models of cognition in psychology (for an overview, see Chaiken \& Trope, 1999, or Evans, 2004), several address the circumstances under which people prefer to process more or less deliberatively. Two of the most prominent are the elaboration likelihood model (ELM; Petty \& Cacioppo, 1986; Petty \& Wegener, 1999) and the heuristicsystematic model (Chaiken, 1980; Chaiken, Liberman, \& Eagly, 1989; Chen \& Chaiken, 1999). These models offer important insights into what influences people's preferences for deliberation. However, unlike the task cuing account, they largely focus on responses to persuasive messages. Also, both the ELM and the heuristic-systematic model implicitly assume that systematic processing is more accurate than less deliberative processing. In contrast, the task cuing account does not presuppose (and participants do not believe) that intuitive thought is necessarily an inferior alternative to rational analysis.

The ELM posits two routes to persuasion-a central route, which involves in-depth, effortful processing of information, and a peripheral route, which entails less effortful processing focused largely on superficial cues. Whether arguments are processed along the central or peripheral route depends on both motivation and ability. Motivational factors that increase central route processing include the personal relevance of an issue (Petty \& Cacioppo, 1984) and the person's chronic tendency to process systematically (Cacioppo, Petty, \& Morris, 1983). Ability factors that increase central route processing include having sufficient time to process pertinent information (Ratneshwar \& Chaiken, 1991) and freedom from distraction (Petty, Wells, \& Brock, 1976).

Beyond the fact that the ELM deals exclusively with responses to persuasive arguments, there are important differences between it and the task cuing account. For example, the ELM is silent about the effects of many of the factors that fall under the umbrella of task cuing. For instance, consider the finding (Study 2) that more complex choice dilemmas tend to engender a preference for choosing rationally rather than intuitively. The ELM does not specify that complex messages should increase central-route processing. Rather, it specifies an interaction between message complexity and a preexisting inclination to process via a central or peripheral route-those processing via the central route should be more persuaded by a complex message (assuming the arguments are valid), but those processing via the peripheral route should be more persuaded by simple, readily comprehensible messages.

This highlights a deeper distinction between the ELM and the approach taken here. The ELM implicitly assumes that people believe that central-route processing leads to greater accuracy or "correctness." Thus, a variable that motivates people to value correctness (e.g., issue involvement or importance), or allows them the cognitive resources to process information in greater depth (e.g., the absence of distraction), should, ceteris paribus, increase reliance on central-route processing and decrease reliance on peripheral-route processing. This assumption sidesteps the question the current research sets out to answer: Under what circum-

\footnotetext{
${ }^{6}$ In contrast to Beach and Mitchell's (1978) contingency model and the task cuing account, the adaptive decision maker framework predicts less rational processing when choices are complex. This difference is addressed below.
} 
stances do people view rational or intuitive processing as best suited to making effective decisions? The current results show that rather than believing, across-the-board, that more rational processing leads to better outcomes, under many circumstances people prefer to listen to their hearts rather than their heads, even when the stakes are high.

Like the ELM, Chaiken and colleagues' heuristic-systematic model (Chaiken, 1980; Chaiken et al., 1989; Chen \& Chaiken, 1999) posits two modes of thought-effortful, deliberate, and analytical systematic processing; and heuristic processing, which is less effortful and relies on cognitive shortcuts or rules of thumb. For present purposes, the most important differences between the two models are (a) the heuristic-systemic model's emphasis on the perceived applicability of heuristics and (b) its explicit acknowledgment that an enhanced motivation to be accurate might lead to more or less emphasis on systematic thought, depending on the characteristics of the problem.

The heuristic-systematic model's treatment of heuristic applicability is, in some ways, similar to the current account of task cuing. According to the heuristic-systematic model, "a heuristic will only exert a judgmental impact to the extent that it is applicable to the current judgmental task or domain" (Chen \& Chaiken, 1999, p. 83). Applicability might result from a feature-level overlap, or match, between the heuristic and the problem at hand, or a deliberate judgment that a heuristic is appropriate in a given context (applicability in this sense is similar, in the ELM, to central-route processing of source cues such as attractiveness).

However, a critical difference between task cuing and applicability as defined by the heuristic-systematic model is the specificity of the matching or applicability. According to the heuristic-systematic model, matching occurs between features of the specific heuristic and the task at hand. For example, the heuristic "expert sources can be trusted" matches a task in which one is asked to evaluate the claims made in a New York Times editorial (Chen \& Chaiken, 1999). The task cuing account, in contrast, takes a much broader view of how matching might occur. Similarities between the features of a decision problem and broader features of intuition or reason, rather than specific characteristics of a given heuristic, cue either rational or intuitive decision strategies.

This distinction is a reflection of a deeper difference between the two approaches in how nondeliberative thinking is conceptualized. In the heuristic-systematic model, the alternatives to deliberative thought are a set of relatively simple heuristics, or rules of thumb, such as "experts can be trusted" or "longer arguments are more convincing." Although intuitive thought does indeed sometimes consist of these simple heuristics, it can also be quite complex and involve the integration of many different features of a stimulus (Betsch, Plessner, Schwieren, \& Gutig, 2001; Dijksterhuis, 2004; Kahneman \& Frederick, 2002) and reflect many years of experience in a given domain (Hammond, 1996).

\section{When Does Complexity Cue Rationality?}

In Study 2, increased complexity enhanced participants' inclination to choose on the basis of reason. This is consistent with Beach and Mitchell's (1978) contingency model, but it is notably at variance with other strategy selection models that posit that increased complexity (i.e., a greater number of options, or more features per option) prompts more heuristic processing (e.g., Payne et al., 1993). One possible explanation for this apparent contradiction is that the relationship between complexity and rational processing may be curvilinear. A moderate level of complexity may cue rational processing, but a very high level might exceed one's cognitive capacity, prompting a fallback to a more holistic and intuitive mode of decision making. There was no evidence of such a curvilinear relationship in Study 2, but it might be more likely to emerge when decision makers are asked to integrate complex information online, with limited time and without external decision aids.

\section{Are People's Intuitions About Intuition Correct?}

So far, we have said little about the extent to which the influence of task cuing on strategy selection is normatively appropriate or defensible. This is largely because it is still the case that all too little is known about the circumstances under which deliberate decisions are superior to intuitive decisions or vice versa. Interestingly, however, the implications of some recent work on the subject conflicts with our participants' thoughts on the matter. In particular, Dijksterhuis et al. (2006) found that for choices between objects with many different attributes, the quality of people's choices and their satisfaction with what they chose declined with the amount of rational thought devoted to the choice. Dijksterhuis et al. argued that this was due to the superiority of intuition (or, as they put it, "unconscious thought") at integrating the multiple trade-offs inherent in complex choices. This is directly counter to the responses of our participants, who thought that more complex choices should be made rationally, not intuitively. The claims made by Dijksterhuis and colleagues are controversial (González-Vallejo, Lassiter, Bellezza, \& Lindberg, 2008; Lassiter, Lindberg, González-Vallejo, Bellezza, \& Phillips, 2009) and so it remains to be seen who is right, or in what circumstances these very different viewpoints are most apt.

Taking a broader view of the effectiveness of intuitive choice, an important cautionary note is sounded by the substantial literature comparing the relative accuracy of statistical (i.e., formulabased) and clinical (i.e., "in the head") judgment in predictions of phenomena from mental illness to parole violations to college performance. This literature shows that, time and time again, actuarial formulas outperform expert judges (Dawes, Faust, \& Meehl, 1989). Although this literature leaves open exactly how judges are making their decisions (e.g., judges may be engaging in a very deliberative process of weighting and adding different cues, but may be weighting cues incorrectly or ignoring important cues entirely), these results do call into question how much confidence should be placed in intuition, even expert intuition, at least in domains in which an actuarial formula can be empirically derived.

\section{Limitations and Future Directions}

In the present research, we attempted to vary a single cue in each study, holding constant other factors. Although this approach makes an examination of the task cuing hypothesis more tractable methodologically, it does not permit an examination of 
the possible interactive effects of multiple cues-and most real-world choices, of course, involve multiple cues to intuition or reason. The simplest possibility is that the effects of multiple cues are additive. We found some support for this in Study 1C, in which outcome evaluability and the sequential versus all-atonce nature of the choice contributed independently to a preference for deciding rationally. However, we did not examine this possibility systematically, and it is certainly possible that some cues might have interactive effects-a possibility that we leave to future research.

Past theoretical accounts of how decision makers select choice strategies have focused on two factors: the motivation to exert cognitive effort and the ability to do so (e.g., Chaiken, 1980; Payne, Bettman, \& Johnson, 1993; Petty \& Cacioppo, 1986). This focus is entirely reasonable: Ability and motivation surely play a large role in the selection of a decision strategy. However, the results reported here suggest that an exclusive focus on these two factors leaves out much of what affects people's choice of decision strategies. The current research is an attempt to broaden the picture by examining a variety of different choices and identifying a variety of strategy-selection cues.

Although we have identified some important characteristics of different choices that cue an intuitive or rational decision strategy, we do not suppose that we have exhaustively covered all possible cues. In particular, we have discussed cues arising from characteristics of the choice task, but cues arising from people's current mental states-that is, state cues-might prove equally important (Cone, Inbar, \& Gilovich, 2010). For example, because of the deliberate nature of rational thought, might the mental state of carefulness and caution produced by the prospect of a loss or a sad mood have the same effect as a sense of disfluent processing (Alter et al., 2007; Simmons \& Nelson, 2006) and lead to a preference for rationality? It makes rational sense (and, conveniently, it also feels right) that the exploration of these sorts of internal state cues is likely to provide additional insight into people's intuitions about when it is best to decide intuitively or deliberately.

\section{References}

Alter, A., Oppenheimer, D., Epley, N., \& Eyre, R. (2007). Overcoming intuition: Metacognitive difficulty activates analytical reasoning. Journal of Experimental Psychology: General, 136, 569-576. doi:10.1037/ 0096-3445.136.4.569

Ambady, N., Bernieri, F. J., \& Richeson, J. A. (2000). Toward a histology of social behavior: Judgmental accuracy from thin slices of the behavioral stream. In M. P. Zanna (Ed.), Advances in experimental social psychology (Vol. 32, pp. 201-271). New York, NY: Academic Press.

Aronson, E., \& Mills, J. (1959). The effect of severity of initiation on liking for a group. Journal of Abnormal and Social Psychology, 59, 177-181. doi: $10.1037 / \mathrm{h} 0047195$

Bargh, J. A. (1997). The automaticity of everyday life. In R. S. Wyer Jr. (Ed.), The automaticity of everyday life: Advances in social cognition (Vol. 10, pp. 1-61). Mahwah, NJ: Erlbaum.

Baron, J. (1988). Thinking and deciding. New York, NY: Cambridge University Press.

Beach, L. R. (1990). Image theory: Decision making in personal and organizational contexts. Chichester, England: Wiley.

Beach, L. R., \& Mitchell, T. R. (1978). A contingency model for the selection of decision strategies. Academy of Management Review, 3, 439-449. doi:10.2307/257535

Betsch, T., Plessner, H., Schwieren, C., \& Gutig, R. (2001). I like it but I don't know why: A value-account approach to implicit attitude formation. Personality and Social Psychology Bulletin, 27, 242-253. doi: 10.1177/0146167201272009

Cacioppo, J. T., Petty, R. E., \& Morris, K. J. (1983). Effects of need for cognition on message evaluation, recall, and persuasion. Journal of Personality and Social Psychology, 45, 805-818. doi:10.1037/00223514.45.4.805

Chaiken, S. (1980). Heuristic versus systematic information processing and the use of source versus message cues in persuasion. Journal of Personality and Social Psychology, 39, 752-766. doi:10.1037/00223514.39.5.752

Chaiken, S., Liberman, A., \& Eagly, A. H. (1989). Heuristic and systematic information processing within and beyond the persuasion context. In J. Uleman \& J. Bargh (Eds.), Unintended thought: Limits of awareness, intention, and control (pp. 212-252). New York, NY: Guilford Press.

Chaiken, S., \& Trope, Y. (1999). Dual-process theories in social psychology. New York, NY: Guilford Press.

Chen, S., \& Chaiken, S. (1999). The heuristic-systematic model in its broader context. In S. Chaiken \& Y. Trope (Eds.), Dual-process theories in social psychology (pp. 73-96). New York, NY: Guilford Press.

Cone, J., Inbar, Y., \& Gilovich, T. (2010). Choosing as you feel: Mental states cue choice strategies. Manuscript in preparation.

Cooksey, R. W. (1996). Judgment analysis: Theory, methods, and applications. San Diego, CA: Academic Press.

Cooper, J. (1980). Reducing fears and increasing assertiveness: The role of dissonance reduction. Journal of Experimental Social Psychology, 16, 199-213. doi:10.1016/0022-1031(80)90064-5

Correll, J., Park, B., Judd, C. M., \& Wittenbrink, B. (2002). The police officer's dilemma: Using ethnicity to disambiguate potentially threatening individuals. Journal of Personality and Social Psychology, 83, 1314-1329. doi:10.1037/0022-3514.83.6.1314

Dawes, R. M., Faust, D., \& Meehl, P. E. (1989, March 31). Clinical vs. actuarial judgment. Science, 243, 1668-1674. doi:10.1126/ science. 2648573

Denes-Raj, V., \& Epstein, S. (1994). Conflict between intuitive and rational processing: When people behave against their better judgment. Journal of Personality and Social Psychology, 66, 819-829. doi: 10.1037/0022-3514.66.5.819

Devine, P. G. (1989). Stereotypes and prejudice: Their automatic and controlled components. Journal of Personality and Social Psychology, 56, 5-18. doi:10.1037/0022-3514.56.1.5

Dijksterhuis, A. (2004). Think different: The merits of unconscious thought in preference development and decision making. Journal of Personality and Social Psychology, 87, 586-598. doi:10.1037/0022-3514.87.5.586

Dijksterhuis, A., Bos, M. W., Nordgren, L. F., \& van Baaren, R. B. (2006, February 17). On making the right choice: The deliberation-withoutattention effect. Science, 311, 1005-1007. doi:10.1126/science.1121629

Dunning, D., \& Stern, L. B. (1994). Distinguishing accurate from inaccurate eyewitness identifications via inquiries about decision processes. Journal of Personality and Social Psychology, 67, 818-835. doi: 10.1037/0022-3514.67.5.818

Ellis, H. D. (1984). Practical aspects of face memory. In G. L. Wells \& E. F. Loftus (Eds.), Eyewitness testimony: Psychological perspectives (pp. 12-37). Cambridge, England: Cambridge University Press.

Epstein, S. (1991). Cognitive-experiential self-theory: An integrative theory of personality. In R. Curtis (Ed.), The self with others: Convergences in psychoanalytic, social, and personality psychology (pp. 111-137). New York, NY: Guilford Press.

Epstein, S. (1994). An integration of the cognitive and psychodynamic unconscious. American Psychologist, 49, 709-724. doi:10.1037/0003066X.49.8.709 
Epstein, S., Pacini, R., Denes-Raj, V., \& Heier, H. (1996). Individual differences in intuitive-experiential and analytical-rational thinking styles. Journal of Personality and Social Psychology, 71, 390-405. doi:10.1037/0022-3514.71.2.390

Evans, J. (2004). History of the dual process theory in reasoning. In K. I. Manktelow \& M. C. Chung (Eds.), Psychology of reasoning: Theoretical and historical perspectives (pp. 241-266). Hove, England: Psychology Press.

Evans, J. (2007). Hypothetical thinking: Dual processes in reasoning and judgment. New York, NY: Psychology Press.

Fiske, S. (1989). Examining the role of intent: Toward understanding its role in stereotyping and prejudice. In J. Uleman \& J. Bargh (Eds.), Unintended thought (pp. 256-283). New York, NY: Guilford Press.

Gigerenzer, G. (2007). Gut feelings: The intelligence of the unconscious. New York, NY: Viking.

Gilovich, T. (1991). How we know what isn't so: The fallibility of human reason in everyday life. New York, NY: Free Press.

Gilovich, T., Griffin, D., \& Kahneman, D. (Eds.). (2002). Heuristics and biases: The psychology of intuitive judgment. Cambridge, England: Cambridge University Press.

Gladwell, M. (2005). Blink: The power of thinking without thinking (1st ed.). New York, NY: Little, Brown.

González-Vallejo, C., Lassiter, G. D., Bellezza, F. S., \& Lindberg, M. J. (2008). "Save angels perhaps": A critical examination of unconscious thought theory and the deliberation-without-attention effect. Review of General Psychology, 12, 282-296. doi:10.1037/a0013134

Haidt, J. (2001). The emotional dog and its rational tail. Psychological Review, 108, 814-834. doi:10.1037/0033-295X.108.4.814

Hall, P. (1980). Great planning disasters. London, England: Weidenfeld \& Nicolson.

Hammond, K. R. (1996). Human judgment and social policy: Irreducible uncertainty, inevitable error, unavoidable injustice. New York, NY: Oxford University Press.

Hammond, K. R., Hamm, R. M., Grassia, J., \& Pearson, T. (1987). Direct comparison of the efficacy of intuitive and analytical cognition in expert judgement. IEEE Transactions on Systems, Man and Cybernetics, 17, 753-770.

Hay, D. C., Young, A. W., \& Ellis, H. D. (1986). What happens when a face rings a bell? The automatic processing of famous faces. In H. D. Ellis, M. A. Jeeves, F. Newcombe, \& A. Young (Eds.), Aspects of face processing (pp. 136-144). Dordrecht, the Netherlands: Martinus Nijhoff.

Hogarth, R. M. (2001). Educating intuition. Chicago, IL: University of Chicago Press.

James, W. (1950). The principles of psychology. New York, NY: Dover. (Original work published 1890)

Judd, C. M., Blair, I. V., \& Chapleau, K. M. (2004). Automatic stereotypes vs. automatic prejudice: Sorting out the possibilities in the Payne (2001) weapon paradigm. Journal of Experimental Social Psychology, 40, 7581. doi:10.1016/S0022-1031(03)00063-5

Kahneman, D. (2003). A perspective on judgment and choice: Mapping bounded rationality. American Psychologist, 58, 697-720. doi:10.1037/ 0003-066X.58.9.697

Kahneman, D., \& Frederick, S. (2002). Representativeness revisited: Attribute substitution in intuitive judgment. In T. Gilovich, D. Griffin, \& D. Kahneman (Eds.), Heuristics and biases: The psychology of intuitive judgment (pp. 49-81). New York, NY: Cambridge University Press.

Kawakami, K., Dovidio, J. F., \& van Kamp, S. (2005). Kicking the habit: Effects of nonstereotypic association training on the application of stereotypes. Journal of Experimental Social Psychology, 41, 68-75. doi:10.1016/j.jesp.2004.05.004

Keynes, J. M. (1921). A treatise on probability. London, England: Macmillan.

Klein, G. A. (1998). Sources of power: How people make decisions. Cambridge, MA: MIT Press.
Kruger, J., Wirtz, D., \& Miller, D. T. (2005). Counterfactual thinking and the first instinct fallacy. Journal of Personality and Social Psychology, 88, 725-735. doi:10.1037/0022-3514.88.5.725

Lassiter, G. D., Lindberg, M. J., González-Vallejo, C., Bellezza, F. S., \& Phillips, N. D. (2009). The deliberation-without-attention effect: Evidence for an artifactual interpretation. Psychological Science, 20, 671675. doi:10.1111/j.1467-9280.2009.02347.x

Levine, R. A., \& Campbell, D. T. (1972). Ethnocentrism: Theories of conflict, ethnic attitudes, and group behavior. New York, NY: Wiley.

MacLennan, R. (1993). Interrater reliability with SPSS for Windows 5.0. The American Statistician, 47, 292-296. doi:10.2307/2685289

Miller, D. T., \& Taylor, B. R. (1995). Counterfactual thought, regret, and superstition: How to avoid kicking yourself. In N. J. Roese \& J. M. Olson (Eds.), What might have been: The social psychology of counterfactual thinking (pp. 305-331). Mahwah, NJ: Erlbaum.

Mitchell, T. R., \& Beach, L. R. (1990). Do I love thee? Let me count: Toward an understanding of intuitive and automatic decision making. Organizational Behavior and Human Decision Processes, 47, 1-20. doi:10.1016/0749-5978(90)90044-A

Myers, D. G. (2002). Intuition: Its powers and perils. New Haven, CT: Yale University Press.

Pacini, R., \& Epstein, S. (1999). The relation of rational and experiential information processing styles to personality, basic beliefs, and the ratiobias phenomenon. Journal of Personality and Social Psychology, 76, 972-987. doi:10.1037/0022-3514.76.6.972

Payne, J. W., Bettman, J. R., \& Johnson, E. J. (1993). The adaptive decision maker. Cambridge, England: Cambridge University Press.

Petty, R. E., \& Cacioppo, J. T. (1984). The effects of involvement on response to argument quantity and quality: Central and peripheral routes to persuasion. Journal of Personality and Social Psychology, 46, 69-81. doi:10.1037/0022-3514.46.1.69

Petty, R. E., \& Cacioppo, J. T. (1986). The elaboration likelihood model of persuasion. In L. Berkowitz (Ed.), Advances in experimental social psychology (Vol. 19, pp. 123-205). New York, NY: Academic Press.

Petty, R. E., \& Wegener, D. T. (1999). The elaboration likelihood model: Current status and controversies. In S. Chaiken \& Y. Trope (Eds.), Dual-process theories in social psychology (pp. 37-72). New York, NY: Guilford Press.

Petty, R. E., Wells, G. L., \& Brock, T. C. (1976). Distraction can enhance or reduce yielding to propaganda: Thought disruption versus effort justification. Journal of Personality and Social Psychology, 34, 874884. doi:10.1037/0022-3514.34.5.874

Ratneshwar, S., \& Chaiken, S. (1991). Comprehension's role in persuasion: The case of its moderating effect on the persuasive impact of source cues. The Journal of Consumer Research, 18, 52-62. doi: $10.1086 / 209240$

Risen, J. L., \& Gilovich, T. (2007). Another look at why people are reluctant to exchange lottery tickets. Journal of Personality and Social Psychology, 93, 12-22. doi:10.1037/0022-3514.93.1.12

Risen, J. L., \& Gilovich, T. (2008). Why people are reluctant to tempt fate. Journal of Personality and Social Psychology, 95, 293-307. doi: 10.1037/0022-3514.95.2.293

Ross, L. D., Amabile, T. M., \& Steinmetz, J. L. (1977). Social roles, social control, and biases in social perception processes. Journal of Personality and Social Psychology, 35, 485-494. doi:10.1037/0022-3514.35.7.485

Schwarz, N. (1990). Feelings as information: Informational and motivational functions of affective states. In E. T. Higgins \& R. M. Sorrentino (Eds.), Handbook of motivation and cognition (pp. 527-561). New York, NY: Guilford Press

Simmons, J. P., \& Nelson, L. (2006). Intuitive confidence: Choosing between intuitive and nonintuitive alternatives. Journal of Experimental Psychology: General, 135, 409-428. doi:10.1037/0096-3445.135.3.409 Sloman, S. A. (1996). The empirical case for two systems of reasoning. Psychological Bulletin, 119, 3-22. doi:10.1037/0033-2909.119.1.3 
Stanovich, K. E. (2004). The robot's rebellion: Finding meaning in the age of Darwin. Chicago, IL: University of Chicago Press.

Stanovich, K. E., \& West, R. F. (2000). Individual differences in reasoning: Implications for the rationality debate? Behavioral and Brain Sciences, 23, 645-665. doi:10.1017/S0140525X00003435

Tversky, A., \& Kahneman, D. (1982). Evidential impact of base rates. In D. Kahneman, P. Slovic, \& A. Tversky (Eds.), Judgment under uncertainty: Heuristics and biases (pp. 117-128). New York, NY: Cambridge University Press.
Wilson, T. D., \& Schooler, J. W. (1991). Thinking too much: Introspection can reduce the quality of preferences and decisions. Journal of Personality and Social Psychology, 60, 181-192. doi:10.1037/00223514.60.2.181

Received May 15, 2009

Revision received March 13, 2010

Accepted March 27, 2010 